\title{
Determination, distribution, and environmental fate of Bacillus thuringiensis spores in various honeybee matrices after field application as plant protection product
}

\author{
Abdulrahim T. Alkassab ${ }^{1}$ (D) Hannes Beims ${ }^{2} \cdot$ Martina Janke $^{2} \cdot$ Jens Pistorius $^{1}$
}

Received: 11 January 2022 / Accepted: 21 February 2022 / Published online: 26 February 2022

(c) The Author(s) 2022

\begin{abstract}
The increasing use of Bacillus thuringiensis (Bt)-based plant protection products (PPPs) has recently raised some concerns regarding their environmental accumulation and possible chronic exposure of non-target species, including pollinators, to higher than expected doses. The exposure level of such microbial PPPs in bee's matrices under field conditions has not yet been described. Therefore, the current study aims at evaluating the realistic exposure level and comparing the distributions and persistence of Bt spores under field conditions. A field trial with spray application in oilseed rape (Brassica napus) as a representative bee-attractive crop was conducted. During the experimental period, different matrices, including honeybeecollected and -stored matrices as well as bee larvae and dead bees, were collected and analyzed using newly established methods. The concentration of Bt spores in the various matrices was quantified. The results show high levels of Bt spores in honey sac and pollen pellets with reduction over time but no reduction of Bt spores in the stored matrices within the colony, i.e., nectar and bee bread, over time. Our results show for the first time the exposure level of bees to Bt spores under realistic field conditions and are fundamentally important for assessing potential exposure and risks for pollinators.
\end{abstract}

Keywords Apis mellifera $\cdot$ Microbial plant protection products $\cdot$ Non-target organisms $\cdot$ Microbial insecticide

\section{Introduction}

Nowadays, the growing world population requires constant high crop yields. To avoid losses caused by weeds, pests, and diseases, which can reach $37 \%$ of all potential crops (Pimentel 1997), farmers follow several approaches. Integrated pest management (IPM) is a general approach, including chemical plant protection products (PPPs) to suppress pest populations below the economic threshold (Peshin et al. 2009). However, increasing numbers of studies have shown the potential adverse effects of chemical PPPs on insect

Responsible Editor: Giovanni Benelli

Abdulrahim T. Alkassab

abdulrahim.alkassab@julius-kuehn.de

1 Julius Kühn-Institut (JKI), Federal Research Centre for Cultivated Plants, Institute for Bee Protection, Braunschweig, Germany

2 Lower Saxony State Office for Consumer Protection and Food Safety (LAVES), Institute for Apiculture, Celle, Germany pollinators, including Apis and non-Apis bees, leading to a wide range of microbial pest-controlling products (MPCPs) being developed as more specific and safer alternatives (Köhl et al. 2019). Among the MPCPs, several products containing different strains and isolates of Bacillus thuringiensis (Bt) are applied worldwide as entomopathogen biocontrol agents against insect pests in agriculture and forest (Sanchis and Bourguet 2008; Lacey et al. 2015).

Currently, the commercial formulations based on different isolates of Bt subsp. kurstaki (Btk) and Bt subsp. aizawai (Bta) to control lepidopteran larvae are the most sprayed bioinsecticides in organic and conventional farming (Bravo et al. 2011). These products are recommended to be sprayed repeatedly within a short interval (3-8 days) due to the sensitivity of toxin crystals or spores to abiotic conditions like UV (EFSA Biohaz Panel (EFSA Panel on Biological Hazards), 2016). The formulations contain different compounds to protect spores and toxin crystals (Brar et al. 2006). Previous studies reported that Btk can persist on the leaves' surface over $72 \mathrm{~h}$ after application, decreasing within 28 days to the environmental background level (Bizzarri and Bishop, 2008; Raymond et al. 2010). 
The increasing use of $\mathrm{Bt}$-based products has recently raised concerns regarding environmental $\mathrm{Bt}$ accumulation which can lead to chronic exposure of non-target species, including entomophagous insects and pollinators, to higher doses than expected (Babin et al., 2020). Bt is known for synthesizing a wide range of toxins encoded on large plasmids. Therefore, each subspecies and/or strain can harbor different plasmids, encoding for synthesized toxins related to their biological activity and the potential target insects (Palma et al. 2014). The most studied insecticidal toxins are Cry-toxins as $\delta$-endotoxins affecting the susceptible insects after oral uptake (Bravo et al. 2011 and Bravo et al., 2017; Mendoza-Almanza et al. 2020). Several reports regarding direct and indirect cross-effects of Bt formulations and their toxins across insect taxa and orders recently indicated the semi-specificity of Bt (van Frankenhuyzen 2017; Redmond et al. 2020; Coyle et al. 2000; Babin et al. 2020; NawrotEsposito et al. 2020; Tudoran et al. 2020). Lepidopterantargeted formulation, containing Bta ABTS 1857, has demonstrated increasing mortality of adult and larvae of honeybees after chronic exposure under laboratory conditions (Steinigeweg et al. 2021).

Their foraging activity may expose bees to Bt products, collecting nectar and pollen contaminated after spray application during flowering on various crops and transporting them to the colony. In-hive conditions differ highly from field conditions, e.g., no more UV effects on the spores and/or the products along with higher humidity. With no information about the realistic exposure yet available, the viability and environmental fate of $\mathrm{Bt}$ spores in the collected matrices, i.e., nectar and pollen, after application in different bee-attractive crops have to be investigated. Recently, we considered the distribution of Bt spores within the colony in several matrices after an artificial in-hive feeding experiment, resulting in the presence of $\mathrm{Bt}$ in all matrices at different concentrations over 2-3 weeks (Steinigeweg et al., 2021).

The current study aims at (1) evaluating the realistic exposure level under field conditions after spray application in oilseed rape as a representative bee-attractive crop and (2) comparing the distributions and persistence of Bt spores in different bee-collected and -stored matrices. These results will be of great importance to assess potential exposure and risks for pollinators.

\section{Materials and methods}

\section{Experimental setup and sample collection}

The study was conducted in Celle, Germany, in 2020. Paired fields with treated and untreated winter oilseed rape (Brassica napus) were used as representative bee-attractive crops. The distance between both fields was approximately $2.5 \mathrm{~km}$.

Seven experimental honeybee colonies were set up as a block on the edge of each oilseed rape field. Figure 1 shows

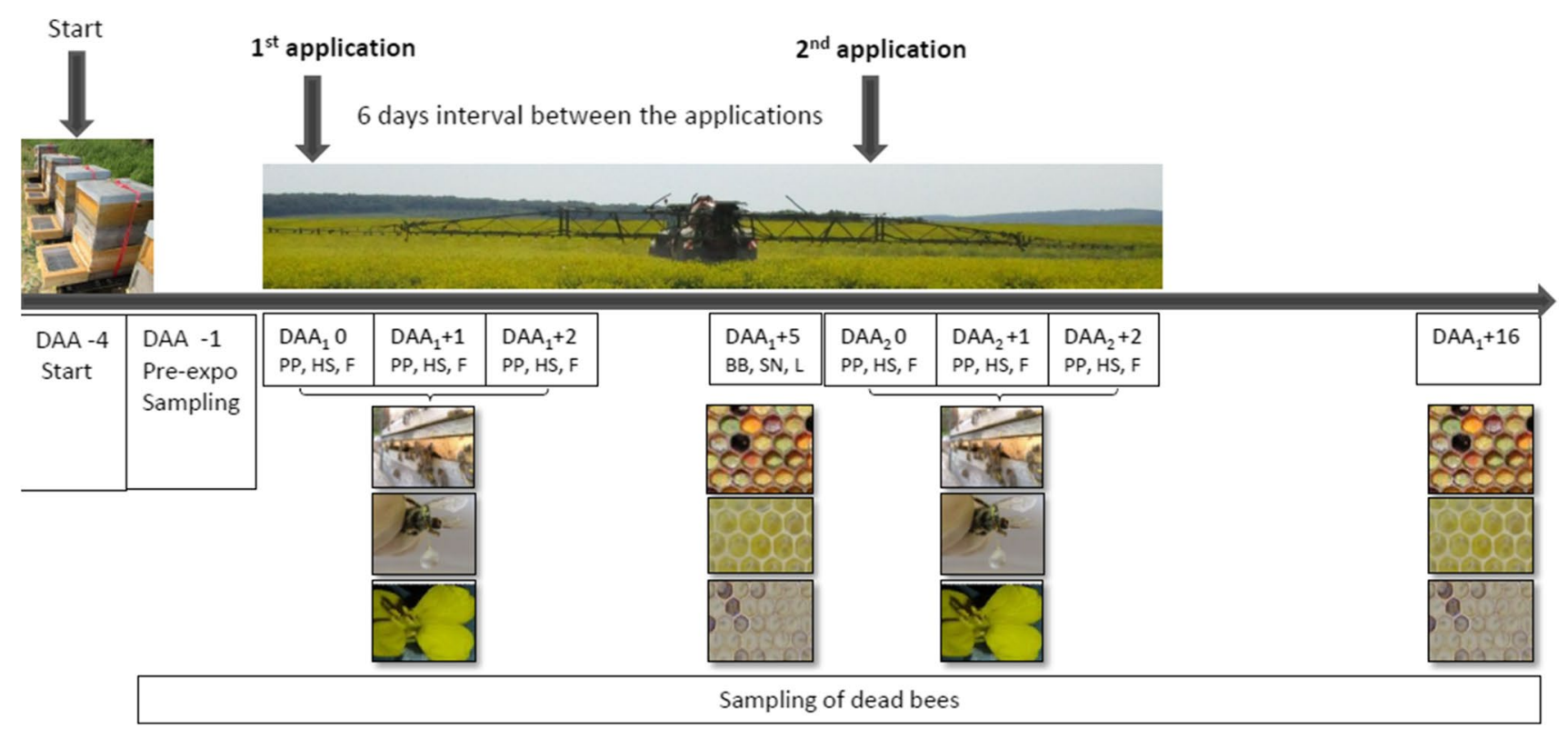

Fig. 1 Experimental design and sampling dates. Seven experimental honeybee colonies were set up as a block on the edge of each oilseed rape field 4 days before the oilseed rape was in full bloom. The Bt-based product containing Bta strain ABTS 1857 was applied during full flowering twice with an interval of 6 days. At the end of flowering, i.e., 16 days after exposure (day after application (DAA), $\left.\mathrm{DAA}_{1}+16\right)$, the colonies were transferred off the field. Various matrices were collected, i.e., honey sac (HS), pollen pellets (PP), flowers $(\mathrm{F})$, bee bread $(\mathrm{BB})$, stored nectar $(\mathrm{SN})$, and larvae (L) 
the time points of the field phase related to the application, i.e., day after application (DAA). The colonies were placed on the edge of the field, 4 days before the oilseed rape was in full bloom (DAA $1-4$; Fig. 1).

At full flowering of winter oilseed rape (BBCH 65), two applications $\left(A_{1}\right.$ and $\left.A_{2}\right)$ were conducted with an interval of 6 days of PPP containing Bta strain ABTS 1857, simulating multiple recommended applications (Fig. 1). The maximum recommended rate of $1.5 \mathrm{~kg} / \mathrm{ha}$ was applied using calibrated commercial sprayers delivering $900 \mathrm{~L} / \mathrm{ha}$, during bee flight. At the end of flowering (BBCH 68-69), i.e., 16 days after exposure $\left(\mathrm{DAA}_{1}+16\right)$, the colonies were transferred off the field (Fig. 1).

Various matrices, including honey sacs and pollen pellets from forager bees, dead bees, larvae, bee bread, and stored nectar, were collected from each colony before application and at different times afterwards (Fig. 1). All samples were stored in the laboratory at $-20{ }^{\circ} \mathrm{C}$ until analysis. Approximately 50 foragers per sampling date were collected and then pollen pellets in the corbiculae were sampled. The honey stomach, i.e., honey sac, of each bee was sampled after dissection of the abdomen and separated from the rest of the digestive tract. The flowers were collected from 10 places from each field and pooled into one sample for each sampling time (Fig. 1). Furthermore, the dead bees were collected from dead traps (modified Gary trap (Gary 1960)) and pooled for each sampling time, pooling at least two bees from each colony to get a sample of approximately $1 \mathrm{~g}$.

\section{Determination of $B t$ in the collected samples}

Samples of different matrices were homogenized and dissolved 1:2 $(w / v)$ in $\mathrm{ddH}_{2} \mathrm{O}$. Tissue lysis was performed in Bead Tubes Type G (Macherey-Nagel, Germany) in a SpeedMill PLUS (Analytik Jena, Germany) for $30 \mathrm{~s}$. Homogenates were used for serial dilution $10^{-1}-10^{-6}$ in $\mathrm{ddH}_{2} \mathrm{O}$ in a final volume of $200 \mu \mathrm{L}$ on an epMotion 5075 (Eppendorf, Germany). Triplicates of $75 \mu \mathrm{L}$ per dilution were plated on LB agar (10 g trypton (Carl Roth, Germany), $5 \mathrm{~g}$ yeast extract (Carl Roth, Germany), $10 \mathrm{~g}$ $\mathrm{NaCl}$ (Carl Roth, Germany), 15 g agar (Carl Roth, Germany), and $1 \mathrm{~L} \mathrm{ddH}_{2} \mathrm{O}$ ) and incubated over night at $37^{\circ} \mathrm{C}$ (Memmert HPP 750, Germany). Bt-typical colonies were finally quantified on each plate and their mean calculated $(\mathrm{cfu} / \mathrm{g})$.

\section{Identification of potential Bt colonies}

Colonies were identified as Bt by qPCR, amplifying a partial sequence of the CryIAa gene (Ogunjimi et al. 2000; Steinigeweg et al. 2021). Accordingly, a random colony was resuspended in $50-\mu \mathrm{L} \mathrm{ddH}_{2} \mathrm{O}$, followed by bacterial lysis at
$95{ }^{\circ} \mathrm{C}$ for $15 \mathrm{~min}$. Cell debris were sedimented at $5000 \times g$ for $5 \mathrm{~min}$, and $1 \mu \mathrm{L}$ of supernatant was used as template for qPCR. PCRs were performed using the LUNA® Universal qPCR Master Mix (New England Biolabs, USA) according to the manufacturer protocol on an AriaMX Real-Time PCR system (Agilent, USA). Samples were identified as Bt-positive when $\mathrm{Cq}<30$ and $80{ }^{\circ} \mathrm{C}<\mathrm{Tm}<81^{\circ} \mathrm{C}$ was obtained (Ruiz-Villalba et al. 2017).

\section{Statistical analysis}

To analyze the differences between matrices over time, linear mixed models (LMMs) were used. Concentrations of Bt spores were set as dependent variables against sampling date and matrices as independent variables; the colony ID served as a random factor. All statistical analyses were conducted using software " $R$ " version 4.0.3 "Bunny-Wunnies Freak Out" (R Core Team 2020) at the significance level of 0.05 . Models were performed with the function lme from the nlme package version 3.1-152 (Pinheiro et al. 2021). Plots used the library ggplot2 (Wickham et al. 2020).

\section{Results and discussion}

\section{Bt concentrations in fresh bee-collected matrices (nectar and pollen)}

Our results show significantly decreasing concentrations in all matrices over 2 days after applications (Fig. 2; GLMM, $p<0.001)$. The level of Bt spores in the honey

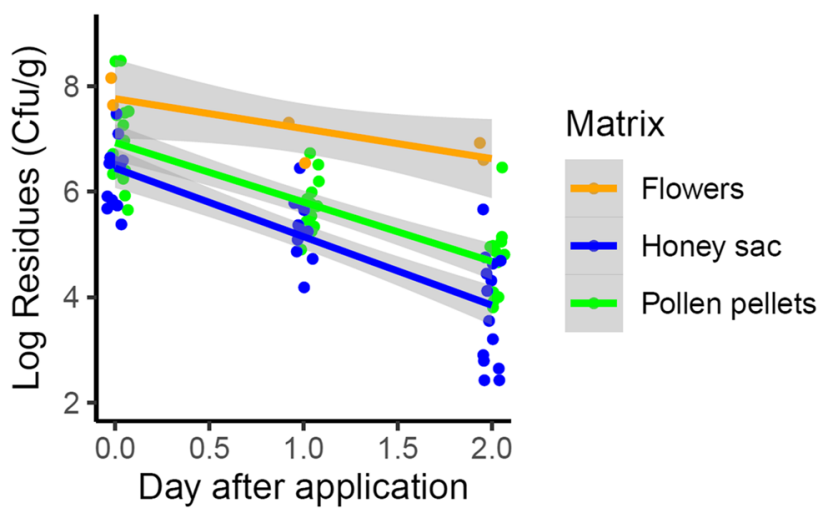

Fig. 2 Concentrations of Bt spores as colony-forming units per gram matrix (cfu/g) over 2 days after application. Sample size is $n=7$ colonies for honey sac and pollen pellets from about 50 foragers per sampling date. One pooled sample of flowers per date was analyzed. A significant decreasing concentration in all matrices over 2 days after applications was found (GLMM, $p<0.001$ ). The level of Bt spores in the honey sac was significantly lower than in pollen pellets (GLMM, $p=0.045$ ) 
sac was significantly lower than in pollen pellets (Fig. 2; GLMM, $p=0.045)$. The maximum detected concentration in pollen pellets was $30.33 \times 10^{7} \mathrm{cfu} / \mathrm{g}$ on $\mathrm{DAA}_{2}+1$ and $3.01 \times 10^{7} \mathrm{cfu} / \mathrm{g}$ on $\mathrm{DAA}_{1}+1$ in the honey sac. Furthermore, the maximum detected concentration on the flowers of oilseed rape was $14.3 \times 10^{7} \mathrm{cfu} / \mathrm{g}$ on $\mathrm{DAA}_{1}+0$ and $4.36 \times 10^{7} \mathrm{cfu} / \mathrm{g}$ on $\mathrm{DAA}_{2}+0$ (Fig. 2). Overall, no significant differences were found between $\mathrm{A}_{1}$ and $\mathrm{A}_{2}$ regarding the detected concentrations (GLMM, $p>0.05$ ). The concentrations spread among $10^{5}-10^{8} \mathrm{cfu} / \mathrm{g}$ on the day of application and between $10^{3}$ and $10^{5} \mathrm{cfu} / \mathrm{g}$ after 2 days. No Bt spores were detected in samples collected before application from both fields or from the untreated field at subsequent dates, except in one sample of honey sacs with a trace concentration of $355 \mathrm{cfu} / \mathrm{g}$ indicating general low background concentrations of Bt.

Generally, few studies show persistence of Bt spores after application of Bt-based MPCPs in the environment, although wide use of Bt-based PPPs is approved worldwide. These PPPs are considered to have a low persistence on foliage under field conditions where the half-life period of viable Bt spores was assumed as a few hours and up to 2 days (Pinnock et al. 1971; Ignoffo and Garcia 1978; Pedersen et al. 1995; Haddad et al. 2005). The rapid degradation of Bt spores is reportedly related to several abiotic factors like UV radiation, temperature, and humidity (Dunkle and Shasha 1988; Ignoffo et al., 1974; Khorramvatan et al. 2014, Sansinenea et al. 2015); therefore, several attempts to develop formulations with better Bt stability under field conditions like UV-protective adjuvants sought to increase efficacy (e.g., Maghsoudi and Jalali 2017). The detected concentrations in our samples were still abundant at a high concentration $>10^{6} \mathrm{cfu} / \mathrm{g} 2$ days after application though significantly decreased in the detected concentrations, confirmed by the results in bee-collected matrices (i.e., pollen and nectar), showing a significant decrease of the Bt concentration 2 days after applications.

\section{Bt concentrations in bee larvae and stored matrices (stored nectar and bee bread)}

The results showed no reduction of the Bt spores in the stored matrices, i.e., nectar and bee bread, within the colony over the sampling time (Fig. 3; GLMM, $p>0.05$ ). The maximum detected concentration in bee bread was $3.96 \times 10^{6} \mathrm{cfu} / \mathrm{g}$, whereas stored nectar presented a range $\left(3.67 \times 10^{6} \mathrm{cfu} / \mathrm{g}\right)$. These results indicate approximately $10 \times$ lower concentrations in the stored than the freshly collected matrices. The detected concentrations in bee larvae spread in a smaller interval, i.e., from undetectable to $2.99 \times 10^{4} \mathrm{cfu} / \mathrm{g}$. Moreover, they differed significantly from the stored matrices (Fig. 3; GLMM, $p=0.009$ ). No Bt spores were detected in

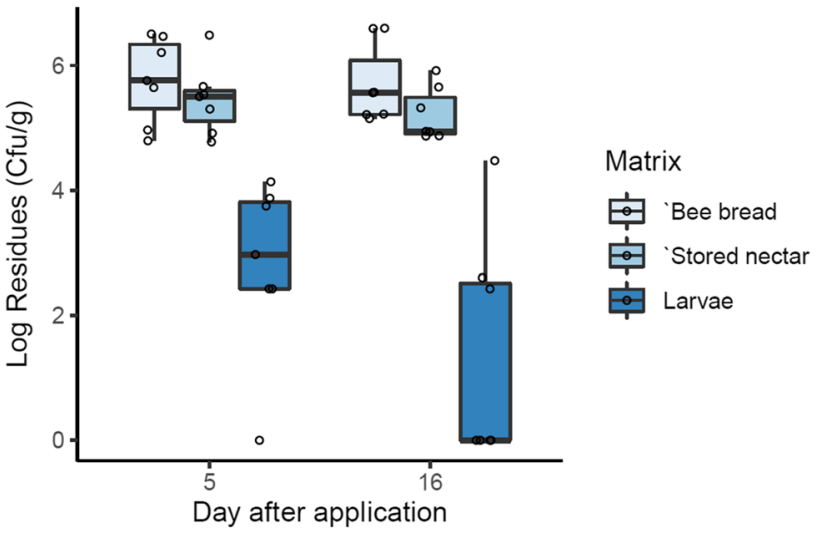

Fig. 3 Concentrations of Bt spores in the stored matrices (nectar and pollen pellets) and bee larvae as colony-forming units per gram matrix (cfu/g) 5 and 16 days after first application. Sample size is $n=7$ colonies per sampling date. No reduction of the Bt spores in the stored matrices, i.e., nectar and bee bread, within the colony over the sampling time was observed (GLMM, $p>0.05$ ). The detected concentrations in bee larvae differed significantly from the stored matrices (GLMM, $p=0.009$ )

all samples as well as in most samples from the colonies in the untreated field, except in two samples from one colony with trace concentrations 267 and $800 \mathrm{cfu} / \mathrm{g}$.

These results concur with our previously published results (Steinigeweg et al., 2021). We found that the detected concentrations in stored food within the colony after feeding Bt-contaminated sugar solution ranged between $10^{5}$ and $10^{6} \mathrm{cfu} / \mathrm{g}$. Nevertheless, we observed decreasing detected concentrations over the 20-day experimental period, perhaps related to the experimental procedure under semi-field conditions, giving the colony only $2 \mathrm{~L}$ of $\mathrm{Bt}$-contaminated sugar solution and uptake to store this amount within a short period. Vandenberg and Shimanuki (1990) investigated the presence of viable spores following storage of the Bt-treated combs against wax moth (Galleria mellonella and Achroia grisella), reporting a long-term presence at ranges of $10^{7} \mathrm{cfu}$ and $10^{4} \mathrm{cfu}$ in comb pieces $(5 \times 10 \mathrm{~cm})$ at $10^{\circ} \mathrm{C}$ and $30^{\circ} \mathrm{C}$ over 12 months storage, respectively. However, honey produced by bees on treated combs contained very low levels of viable Bt spores after 20 weeks. Thus, a longterm presence of $\mathrm{Bt}$ spores can be expected despite the low detected levels.

European Food Safety Agencies (EFSA) suggested the threshold of $10^{5} \mathrm{cfu} / \mathrm{g}$ on plant commodity at harvest time to cover the risk of food-borne poisonings (EFSA Biohaz Panel (EFSA Panel on Biological Hazards), 2016). Our results show the detected concentrations in collected pollen approximately $10^{2}-10^{3}$ above this threshold. Moreover, the detected concentrations in stored nectar or later honey are mostly tenfold higher 


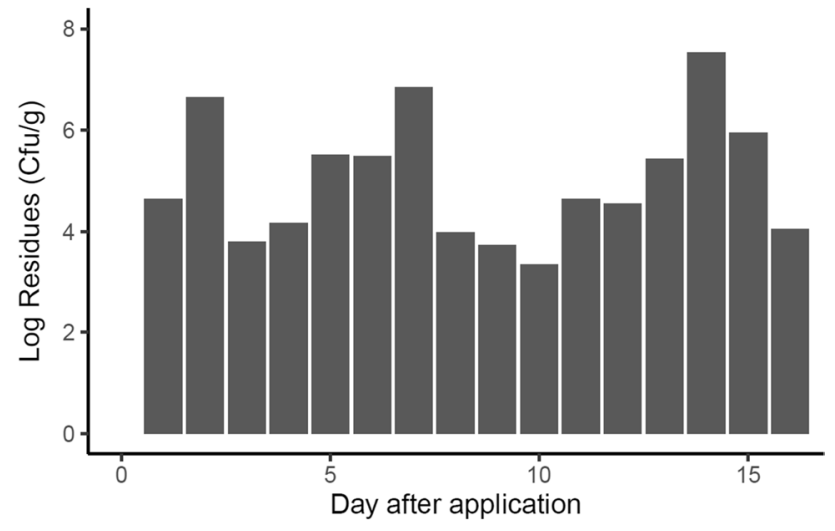

Fig. 4 Concentrations of $\mathrm{Bt}$ spores in dead bees as colony-forming units per gram matrix (cfu/g) over the experimental period. Pooled sample from all colonies with about $10-14$ bees per sampling date was analyzed. High concentrations of Bt spores were detected at a later date after applications, indicating the chronic Bt spore exposure of bees and possible infective properties of $\mathrm{Bt}$

than the threshold, although 10 days after the second application.

The detected concentrations in larvae were significantly lower than the stored matrices, covering a range of $0-2.99 \times 10^{4} \mathrm{cfu} / \mathrm{g}$. Assuming that the L4 larvae weigh about 55-88 mg (Zółtowska et al. 2011), about 12-18 larvae represent the analyzed amount of $1 \mathrm{~g}$; the maximum detected level of Bt spores can be assumed as about $10^{3} \mathrm{cfu} /$ larvae. This level may still be tolerable for larvae, since they were alive during sampling. Steinigeweg et al. (2021) reported high larval mortality under laboratory conditions after exposure to a range of $0.16-32.00 \mu \mathrm{g}$ product/larvae corresponding to concentrations of about $10^{4}-10^{6} \mathrm{cfu} / \mathrm{larvae}$. These concentrations are calculated based on the reported maximum concentrations of $6 \times 10^{13} \mathrm{cfu} / \mathrm{kg}$ of Bta ABTS 1857 in the formulated product (EFSA, 2020). Therefore, further research is needed to assess the tolerable level of Bt for larvae.

\section{Bt concentrations in dead bees}

Bt spores were detected in all samples collected from the treated field after applications. The concentrations ranged from $2.23 \times 10^{3} \mathrm{cfu} / \mathrm{g}$ to $3.42 \times 10^{7} \mathrm{cfu} / \mathrm{g}$ (Fig. 4). Remarkably, high concentrations of $\mathrm{Bt}$ spores were detected at a later date after applications, indicating the chronic Bt spore exposure of bees and possible infective properties of Bt. No Bt spores were detected in all samples taken from the treated field before application or from the control field at all sampling dates.

Although Bt strains are assumed to be selective on target pests, recent reports indicate cross-order effects (van Frankenhuyzen et al. 2017). For example, the
Coleopteran-targeted formulation can cause negative effects on Lepidopteran (Redmond et al. 2020), the Lepidopteran-targeted formulation on Coleopteran and the Dipteran (Coyle et al. 2000; Babin et al. 2020; Nawrot-Esposito et al. 2020), and Diptera-targeted formulation on Coleopteran (Tudoran et al. 2020). Regarding the effects on bees, differences in the sensitivity of adult worker bees to different Bt products were reported (Brighenti et al. 2007; Mommaerts et al. 2010; D'urso V, Mazzeo G, Vaccalluzzo V, Sabella G, Bucchieri F, Viscuso R, Vitale DG, , 2017; Libardoni et al. 2018; Potrich et al. 2018; Steinigeweg et al. 2021). Steinigeweg et al. (2021) reported increased mortality under laboratory conditions after exposure to Bta ABTS 1857 at a range of $10^{6}-10^{7} \mathrm{cfu} / \mathrm{g}$. Other Bt strains also reduced the survival duration of adult bees (Libardoni et al. 2018; Potrich et al. 2018). Studies considered the interactions between single species in the bee gut microbiome and their community dynamics in relation to the bees' health (Engel et al. 2016). Since the applied MPCPs contain living active ingredients, further studies should particularly determine their impact on the composition and development of the honeybee gut microbiome.

\section{Conclusion}

Our study shows for the first time that the viability of $\mathrm{Bt}$ spores differs from honeybee colony conditions to field conditions. Remarkably, although the most used microorganism isolated from the natural environment, the application intensity and formulated products may cause significantly higher exposure levels than the background level. Thus, exhaustive examinations of MPCPs' effect on the honeybee and other bee species under field conditions will help understand the natural role and the behavior of "living active ingredients" for beneficial organisms. This should include several parameters to be long-term-investigated to enable proper risk assessment.

Acknowledgements The authors are grateful to members of the institute for Bee Protection (JKI) for their technical assistance as well as members of the Institute for Apiculture (LAVES) for their support with the carrying out the experiment and analyzing the samples.

Author contribution ATA designed the experiment, performed the statistical analysis of the collected data, and wrote the first draft. MJ conducted the experiment and collected the samples. HB performed the analysis of laboratory procedures. JP supervised the work. All authors have read and approved the manuscript.

Funding Open Access funding enabled and organized by Projekt DEAL. This study was funded by the German Federal Ministry of Food and Agriculture (BMEL). 
Data availability The datasets used and/or analyzed during the current study are available from the corresponding author on reasonable request.

\section{Declarations}

Ethics approval and consent to participate Not applicable.

Consent for publication Not applicable.

Competing interests The authors declare no competing interests.

Open Access This article is licensed under a Creative Commons Attribution 4.0 International License, which permits use, sharing, adaptation, distribution and reproduction in any medium or format, as long as you give appropriate credit to the original author(s) and the source, provide a link to the Creative Commons licence, and indicate if changes were made. The images or other third party material in this article are included in the article's Creative Commons licence, unless indicated otherwise in a credit line to the material. If material is not included in the article's Creative Commons licence and your intended use is not permitted by statutory regulation or exceeds the permitted use, you will need to obtain permission directly from the copyright holder. To view a copy of this licence, visit http://creativecommons.org/licenses/by/4.0/.

\section{References}

Babin A, Nawrot-Esposito MP, Gallet A, Gatti JL, Poirié M (2020) Differential side-effects of Bacillus thuringiensis bioinsecticide on non-target Drosophila flies. Sci Rep 10(1):1-16

Bizzarri MF, Bishop AH (2008) The ecology of Bacillus thuringiensis on the phylloplane: colonization from soil, plasmid transfer, and interaction with larvae of Pieris brassicae. Microb Ecol 56(1):133-139. https://doi.org/10.1007/s00248-007-9331-1

Brar SK, Verma M, Tyagi RD, Valéro JR (2006) Recent advances in downstream processing and formulations of Bacillus thuringiensis based biopesticides. Process Biochem 41(2):323-342. https://doi. org/10.1016/j.procbio.2005.07.015

Bravo A, Likitvivatanavong S, Gill SS, Soberon M (2011) Bacillus thuringiensis: a story of a successful bioinsecticide. Insect Biochem Mol Biol 41(7):423-431. https://doi.org/10.1016/j.ibmb. 2011.02.006

Coyle DR, McMillin JD, Krause SC, Hart ER (2000) Laboratory and field evaluations of two Bacillus thuringiensis formulations, Novodor and Raven, for control of cottonwood leaf beetle (Coleoptera: Chrysomelidae). J Econ Entomol 93(3):713-720

Bravo A, Pacheco S, Gomez I, Garcia-Gomez B, Onofre J, Soberon M (2017) Insecticidal proteins from Bacillus thuringiensis and their mechanism of action. In Bacillus thuringiensis and Lysinibacillus sphaericus (eds Fiuza, L.M. et al.,) ISBN 978-3-319-56677-1, 53-66, (Spinger, Cham, 2017)

Brighenti DM, Carvalho CF, Carvalho GA, Brighenti CRG, Carvalho SM (2007) Bioactivity of Bacillus thuringiensis var. kurstaki (Berliner, 1915) to adults of Apis mellifera Linnaeus, 1758 (Hymenoptera: Apidae). Ciência e Agrotecnologia 31(2):279-289

D’urso V, Mazzeo G, Vaccalluzzo V, Sabella G, Bucchieri F, Viscuso R, Vitale DG (2017) Observations on midgut of Apis mellifera workers (Hymenoptera: Apoidea) under controlled acute exposures to a Bacillus thuringiensis-based biopesticide Apidologie 4815162
EFSA BIOHAZ Panel (EFSA Panel on Biological Hazards), (2016) Scientific opinion on the risks for public health related to the presence of Bacillus cereus and other Bacillus spp. including Bacillus thuringiensis in foodstuffs. EFSA Journal 14(7):4524, 93 pp. https://doi.org/10.2903/j.efsa.2016.4524

Engel P, Kwong WK, McFrederick Q, Anderson KE, Barribeau SM, Chandler JA et al (2016) The bee microbiome: impact on bee health and model for evolution and ecology of host-microbe interactions. MBio, 7(2)

European Food Safety Authority (EFSA), Anastassiadou, M., Arena, M., Auteri, D., Brancato, A., Bura, L., et al (2020) Peer review of the pesticide risk assessment of the active substance Bacillus thuringiensis ssp. aizawai strain ABTS-1857. EFSA Journal 18(10):e06294

European Food Safety Authority (EFSA) (2012) Conclusion on the peer review of the pesticide risk assessment of the active substance Bacillus thuringiensis subsp. kurstaki (strains ABTS 351, PB 54, SA 11, SA 12, EG 2348). EFSA Journal 10(2):2540

Gary NE (1960) A trap to quantitatively recover dead and abnormal honey bees from the hive. J Econ Entomol 53(5):782-785

Haddad MDL, Polanczyk RA, Alves SB, Garcia MDO (2005) Field persistence of Bacillus thuringiensis on maize leaves (Zea mays L.). Brazilian Journal of Microbiology 36(4):309-314

Ignoffo CM, Garcia C (1978) UV-photoinactivation of cells and spores of Bacillus thuringiensis and effects of peroxidase on inactivation. Environ Entomol 7(2):270-272

Ignoffo CM, Hostetter DL, Pinnell RE (1974) Stability of Bacillus thuringiensis and Baculovirus heliothis on soybean foliage. Environ Entomol 3(1):117-119

Köhl J, Booij K, Kolnaar R, Ravensberg WJ (2019) Ecological arguments to reconsider data requirements regarding the environmental fate of microbial biocontrol agents in the registration procedure in the European Union. Biocontrol 64(5):469-487

Lacey LA, Grzywacz D, Shapiro-Ilan DI, Frutos R, Brownbridge M, Goettel MS (2015) Insect pathogens as biological control agents: back to the future. J Invertebr Pathol 132:1-41. https:// doi.org/10.1016/j.jip.2015.07.009

Libardoni G, De Gouvea A, Costa-Maia FM, Lozano ER, de Freitas PF, Colombo FC, et al (2018) Effect of different Bacillus thuringiensis strains on the longevity of Africanized honey bee. Semina: Ciências Agrárias 39(1):329-338

Maghsoudi S, Jalali E (2017) Noble UV protective agent for Bacillus thuringiensis based on a combination of graphene oxide and olive oil. Sci Rep 7(1):1-6

Mendoza-Almanza G, Esparza-Ibarra EL, Ayala-Luján JL, MercadoReyes M, Godina-González S, Hernández-Barrales M, OlmosSoto J (2020) The cytocidal spectrum of Bacillus thuringiensis toxins: from insects to human cancer cells. Toxins 12(5):301

Mommaerts V, Jans K, Smagghe G (2010) Impact of Bacillus thuringiensis strains on survival, reproduction and foraging behaviour in bumblebees (Bombus terrestris). Pest Management Science: Formerly Pesticide Science 66(5):520-525

Nawrot-Esposito MP, Babin A, Pasco M, Poirié M, Gatti JL, Gallet A (2020) Bacillus thuringiensis bioinsecticides induce developmental defects in non-target Drosophila melanogaster larvae. Insects 11(10):697

Ogunjimi AA, Gbenle GO, Olukoya DK, Akinrimisi EO (2000) PCR-based identification of Bacillus thuringiensis isolated from soil samples in Nigiria. Z Naturforsch C J Biosci 55(11-12):987-990

Palma L, Muñoz D, Berry C, Murillo J, Caballero P (2014) Bacillus thuringiensis toxins: an overview of their biocidal activity. Toxins 6(12):3296-3325. https://doi.org/10.3390/toxins6123296

Pedersen JC, Hansen BM, Damgaard PH, Eilenberg J (1995) Dispersal of Bacillus thuringiensis var. kurstaki in an experimental cabbage field. Canadian Journal of Microbiology 41(2):118-125 
Peshin R, Bandral RS, Zhang W, Wilson L, Dhawan AK (2009) Integrated pest management: a global overview of history, programs and adoption. Integrated pest management: innovation-development process $1-49$

Pimentel D (1997) Pest management in agriculture. In: Pimentel D (ed) Techniques for reducing pesticide use: environmental and economic benefits. John Wiley \& Sons, Chichester, pp 1-11

Pinheiro J, Bates D, DebRoy S, Sarkar D (2021) nlme: linear and nonlinear mixed effects models. R package version 3.1-152. Retrieved on 24 March 2021 from https://cran.r-project.org/web/packages/ nlme/

Pinnock DE, Brand RJ, Milstead JE (1971) The field persistence of Bacillus thuringiensis spores. J Invertebr Pathol 18(3):405-411

Potrich M, da Silva RT, Maia F, Lozano ER, Rossi RM, Colombo FC, et al (2018) Effect of entomopathogens on africanized Apis mellifera L.(Hymenoptera: Apidae). Revista Brasileira de Entomologia 62(1):23-28

R Core Team (2020) R: a language and environment for statistical computing. R Foundation for Statistical Computing, Vienna

Raymond B, Wyres KL, Sheppard SK, Ellis RJ, Bonsall MB (2010) Environmental factors determining the epidemiology and population genetic structure of the Bacillus cereus group in the field. PLoS Pathog 6(5):e1000905.

Redmond CT, Wallis L, Geis M, Williamson RC, Potter DA (2020) Strengths and limitations of Bacillus thuringiensis galleriae for managing Japanese beetle (Popillia japonica) adults and grubs with caveats for cross-order activity to monarch butterfly (Danaus plexippus) larvae. Pest Manag Sci 76(2):472-479

Ruiz-Villalba A, van Pelt-Verkuil E, Gunst QD, Ruijter JM, van den Hoff MJB (2017) Amplification of nonspecific products in quantitative polymerase chain reactions (qPCR). Biomol Detect Quantif $14: 7-18$

Sanchis V, Bourguet D (2008) Bacillus thuringiensis: applications in agriculture and insect resistance management. Rev Agron Sustain Dev 28(1):11-20. https://doi.org/10.1051/agro:2007054
Sansinenea E, Salazar F, Ramirez M, Ortiz A (2015) An ultra-violet tolerant wild-type strain of melanin-producing Bacillus thuringiensis. Jundishapur J. Microbiol. 8

Steinigeweg C, Alkassab AT, Beims H, Eckert JH, Richter D, Pistorius J (2021) Assessment of the impacts of microbial plant protection products containing Bacillus thuringiensis on the survival of adults and larvae of the honeybee (Apis mellifera). Environ Sci Pollut Res 28(23):29773-29780

Tudoran A, Nordlander G, Karlberg A, Puentes A (2020) A major forest insect pest, the pine weevil Hylobius abietis, is more susceptible to Diptera-than Coleoptera-targeted Bacillus thuringiensis strains. Pest Manag Sci 77(3):1303-1315

Vandenberg JD, Shimanuki H (1990) Viability of Bacillus thuringiensis and its efficacy for larvae of the greater wax moth (Lepidoptera: Pyralidae) following storage of treated combs. J Econ Entomol 83(3):760-765

van Frankenhuyzen K (2017) Specificity and cross-order activity of Bacillus thuringiensis pesticidal proteins. In Bacillus thuringiensis and Lysinibacillus sphaericus (pp. 127-172). Springer, Cham.

Wickham H, François R, Henry L, Müller K (2020) dplyr: a grammar of data manipulation. R package version 0.8.5. Retrieved Oct. 19, 2020, from https://CRAN.R-project.org/package $=$ dplyr

Zółtowska K, Fraczek R, Lipiński Z (2011) Hydrolases of developing worker brood and newly emerged worker of Apis mellifera carnica. J Apic Sci 55:27-36

Publisher's note Springer Nature remains neutral with regard to jurisdictional claims in published maps and institutional affiliations. 